\title{
Adaptive lighting comfort in the classrooms of educational building and student hostel rooms
}

\author{
Subbarao Yarramsetty ${ }^{1 *}$, Nikhil Siva Deka ${ }^{1}$, and Siva Kumar MVN. ${ }^{1}$ \\ ${ }^{1}$ Department of Civil Engineering, NIT Warangal, Telangana State-506 004, India.
}

\begin{abstract}
The comfort level of occupants inside a building depends on various indoor environment factors like thermal comfort, indoor air quality, and indoor lighting quality. According to studies done on indoor environment quality of buildings, lighting plays a very critical role in determining the occupants comfort level. A proper indoor lighting is very important especially in the classrooms of an educational building as well as in student hostel rooms as it can be said as a vital element, controlling the psychology and comfort of the students and hence a deciding factor in the teaching-learning process. The lighting intensity and its distribution depends on the location of the interior partition as well as the design strategy of the exterior envelop. So, in order to obtain the most occupant friendly results, the impact of various strategies adopted should be evaluated in the early design period itself. This paper adopts a questionnaire-based field surveys which is done in the classrooms of National Institute of Technology Warangal and also in the hostel rooms of 1.8K Ultra Mega hostel of this institute. The main objective of this study includes. 1) To assess the indoor lighting comfort in the classrooms and hostel rooms of National Institute of Technology Warangal through a questionnaire-based lighting comfort study. 2) To identify preferences of subjects in the classroom environment with respect to lighting comfort and 3) To identify the comfort range of lighting intensity inside the classrooms and hostel rooms. SPSS software is used analyse the reliability of survey responses by finding the $\mathrm{P}$ value.
\end{abstract}

\section{Introduction}

The overall satisfaction of occupants inside a building can be improved favourably by enhancing the indoor air quality [1], thermal comfort [2] and indoor lighting quality [3]. Now a days with the increase in interest in health and also the environment, maintaining a proper comfortable environment inside a building is taken as an issue of importance by people in the twenty-first century to maintain health, while increasing productivity and efficiency of the occupants simultaneously. According to studies done on indoor environment quality of buildings, day lighting inside a room plays a very critical role in determining the occupants comfort level [4].

Lighting comfort can be defined as satisfaction of the residents in the given environment. Lighting quality is also dependent on the overall quantity of light. A good quality of lighting in general is contributed by a definite range of quantities of light. Various other parameters which affects the quality of lighting includes the illumination uniformity, good distribution of indoor light, colour characteristics of the lighting and room surfaces, flicker rate and glare [5]. There are many codes or guidelines for lighting design such as Chartered Institution of Building Services Engineers (CIBSE) Code for Interior Lighting [6], Illuminating Engineering Society (IES) Lighting Handbook [7] etc. that provide recommendations for some of the factors like uniformity and glare. A proper indoor lighting comfort is very important especially in the classrooms of an educational building as well as in student hostel rooms as it can be said as a vital element, controlling the psychology [8] and comfort of the students and hence a deciding factor in the teaching-learning process. A classroom requires the appropriate lighting environment that respond to the students as well as the staff sensitiveness. A continuous environmental stress can drain student's physical and mental resources which ultimately affects their performance [9]. Indoor environmental variables like distance from window, distance from board or projector screen, distribution of lighting inside the room, amount of interaction done in classroom etc. affects the lighting comfort sensation of the students. From studies it is found that the stress hormone known as cortisol are more regulated more efficiently by daylight than artificial lighting [10]. So, students should be always provided with access to daylight other than continuous exposure to electrical lighting systems in the building.

\section{Area of Study}

1.8K Ultra Mega hostel rooms and classrooms of Civil Engineering department of National Institute of Technology Warangal is chosen for this study. This study was done in month of September 2019. Warangal is one of the two metropolitan cities in the state of Telangana in

\footnotetext{
*Corresponding author: sraoystp@student.nitw.ac.in
} 
India. During September it mainly has clear and sunny sky with some occasional cloudy periods and rainy days in between. The study area in plan and the view of $1.8 \mathrm{~K}$ Ultra mega hostel is shown in Fig. 1.

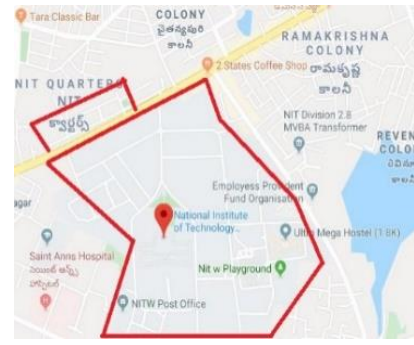

(a)

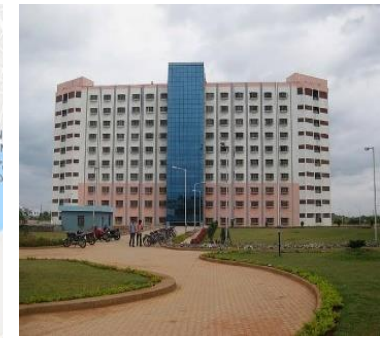

(b)
Fig. 1. (a) NIT Warangal Campus, (b) $1.8 \mathrm{~K}$ Hostel elevation

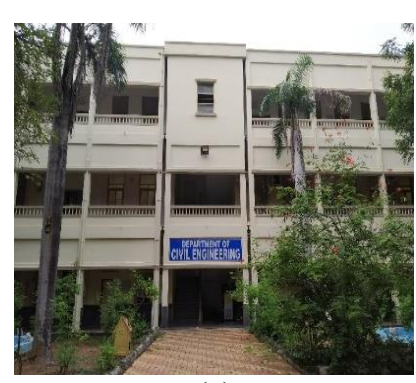

(a)

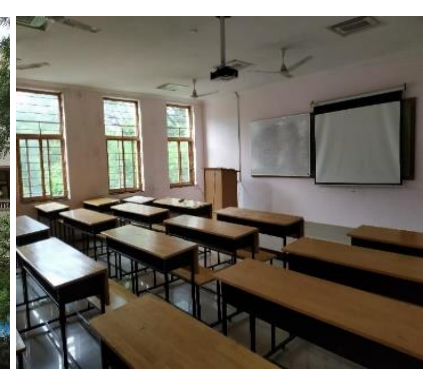

(b)
Fig. 2. (a) Civil Engineering Department, (b) Classroom

The size of each classroom in which data is recorded are same. The vegetation covers near the classrooms are different creating somewhat different indoor lighting conditions for each classroom. The entrance view of Department of civil engineering division and the classroom arrangement is shown in Fig. 2. These classrooms are located in the 2nd floor of the Civil Engineering Department. 1.8K Ultra Mega hostel is a $\mathrm{G}+9$ hostel building. The sizes of each room in the hostel are same but orientation of doors and windows and positions of the rooms vary according its location within the hostel regarding A wing (east facing) and B wing (west facing).Different rooms from different floors as well as different locations are chosen for the study so that varieties of data regarding indoor lighting comfort of students residing in these rooms can be observed.

\section{Methodology}

The lighting intensities (in lux) were measured continuously on hourly basis using the HTC LX-103 Digital Lux Meter instrument. The measurements were taken approximately at the working plane of the classrooms as well as hostel rooms. Data was collected from morning $8 \mathrm{AM}$ to evening $5 \mathrm{PM}$ for a week for the classrooms. The image of the digital lux instrument used for the study is shown in Fig. 3.

This study is carried out to assess their indoor lighting comfort conditions during the students' lesson hours. Data was taken at three positions within the classrooms i.e. near the window side, centre of the room and near the corridor side. The lighting intensity outside the room was also recorded. For the hostel rooms data was recorded for a month from $8 \mathrm{AM}$ to $5 \mathrm{PM}$ for different rooms located at different positions at both the east facing wing $\mathrm{A}$ and the west facing wing $\mathrm{B}$ which is shown in Fig. 4. In the hostel room data was taken near the window, farthest position from the window and also outside the room. Data recorded at different position in the room will help in analysing the light intensity distribution in the rooms.

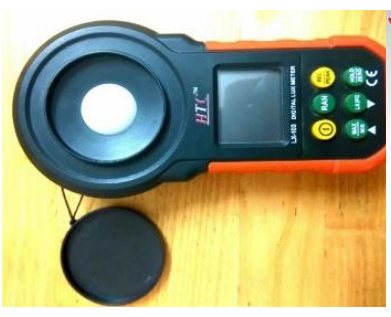

Fig. 3. HTC LX-103 Digital Lux meter

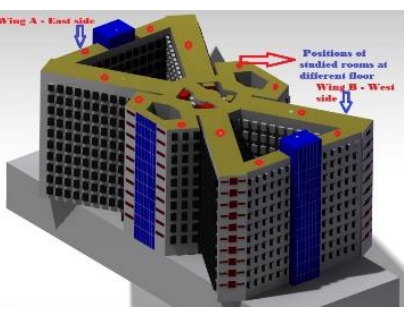

Fig. 4. Location of Study rooms $-3 \mathrm{D}$ view
Also, a questionnaire survey on various aspects of lighting in the selected rooms were conducted to study the subjective response of students to the indoor lighting comfort during daytime for classrooms as well as hostel rooms. The subjective response of the respondents and the daylight intensity recorded were compared to identify the comfort range of the students and also the different factors of discomfort regarding indoor lighting.

\section{Results}

\subsection{Analysis of daylight intensity in the classrooms}

All the studied classrooms are used from morning 8 AM to evening $5 \mathrm{PM}$ for theoretical class purpose as well as seminar room for the students. The teaching learning process is delivered by using both white board and projector screen. So, a proper lighting environment is very necessary to accommodate all these facilities and commencing an efficient transfer of knowledge

These recorded lighting intensity variations with time are plotted in graph to analyse the pattern of variation which shows that there is a major difference in lighting intensity at different positions of the room. Near the window direct sunlight comes into the room and intensity is quite high but at the centre of the room and towards the corridor side intensity of daylight is poor. Except for a few hours, daylighting is well below the recommended comfortable lighting of 500 lux for classroom for a major part of the day. Again near the window daylight intensity is higher than 750 lux of upper limit value and caused discomfort among the students setting near the windows which was revealed after the analysis of the questionnaire survey. Fig. 5, Fig. 6 and Fig. 7 shows the indoor lighting intensity variations at different position of the classrooms in a more meaningful form to extract the pattern. 


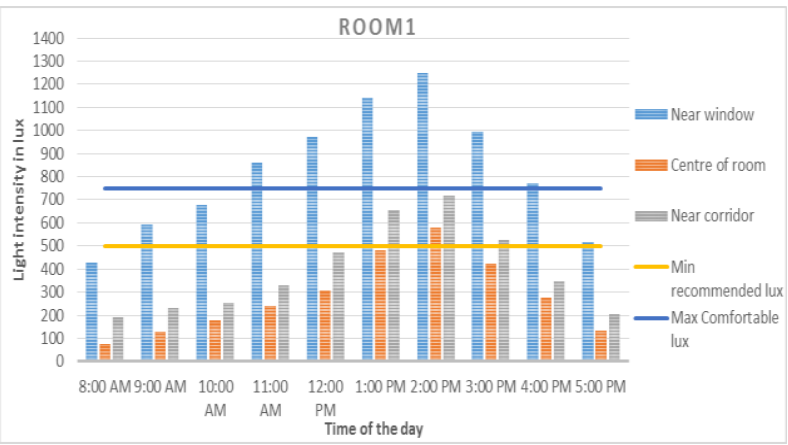

Fig. 5. Variation of indoor daylight intensity, Room \# 1

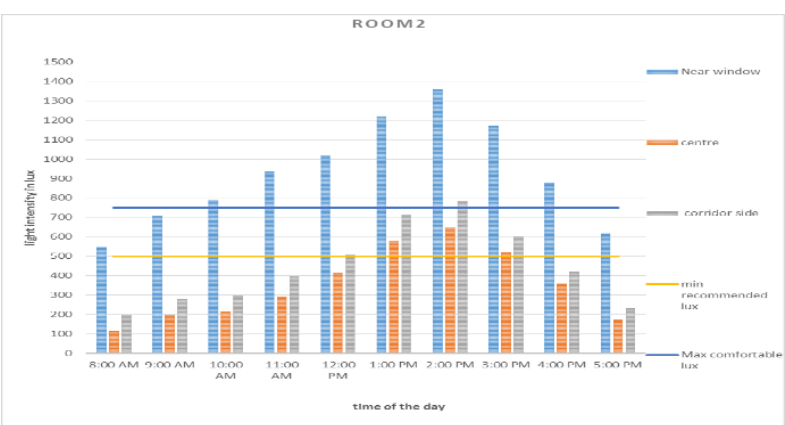

Fig. 6. Variation of indoor daylight intensity, Room \# 2

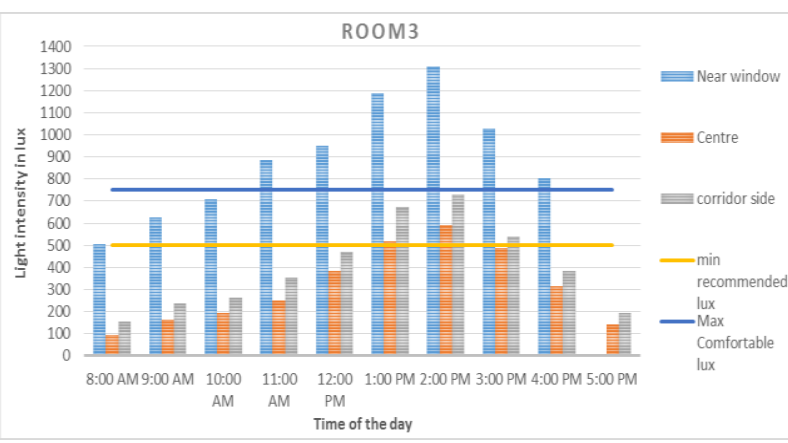

Fig. 7. Variation of indoor daylight intensity, Room \# 3

It was observed that the overall indoor lighting of classroom \# 2 is better than rooms 1 and 3. It is due to the fact that vegetation covers on the corridor side and window side of room 1 and 3 are much denser than room 2 therefore the light intensity outside the rooms are lower which in turn interferes with the indoor lighting of the respected rooms. Fig. 8 shows the variation of lighting intensity outside each classroom over the time.

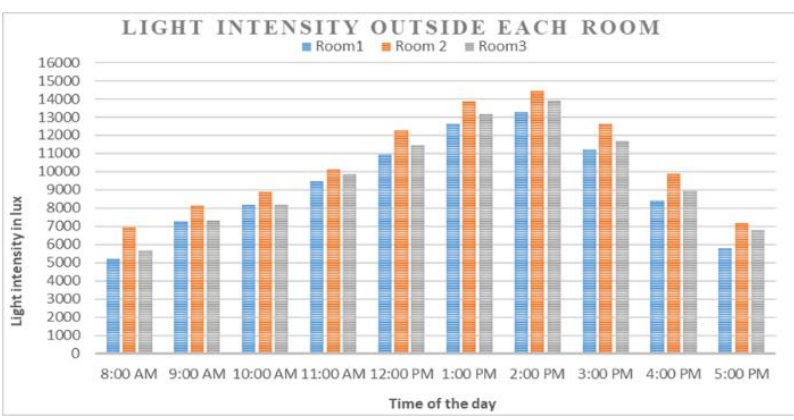

Fig. 8. Avg. Outside lighting intensity
Again, when the average lighting intensity of the day for different position within the room is calculated for 7 days of recorded value, it was found that daylight intensity varies widely for all the 7 days. Some days were bright enough to cause lighting discomfort like thermal irritation and glare whereas some days were dark and cloudy and artificial lighting was needed for smooth running of the classes. Fig.9, Fig10 and Fig.11 shows the variation of average lighting intensities of studied classrooms at different position over the 7 days period.

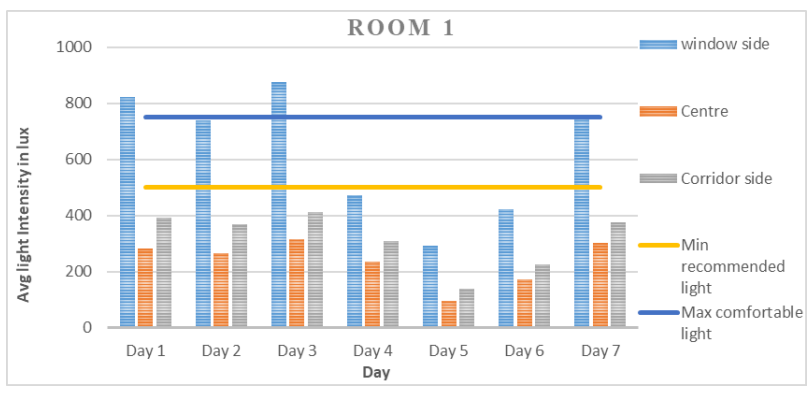

Fig. 9. Weekly Avg. daylight intensity variation, Room \# 1

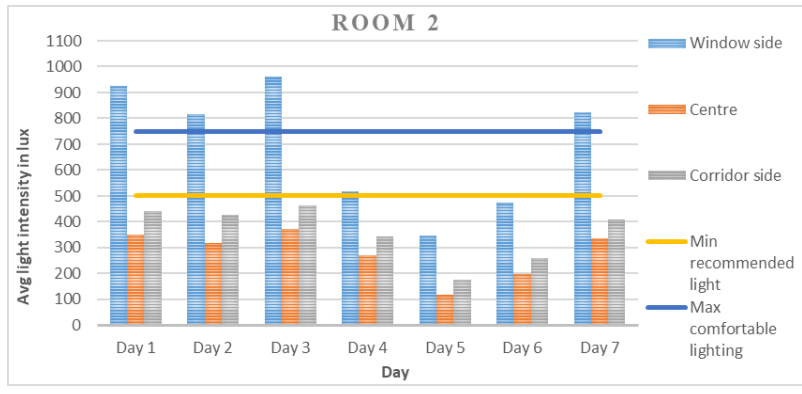

Fig. 10. Weekly Avg. daylight intensity variation, Room \# 2

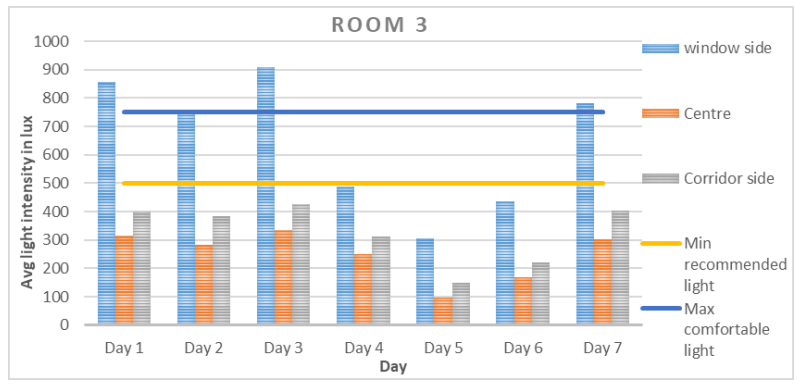

Fig. 11. Weekly Avg. daylight intensity variation, Room \# 3

From the Fig. 9, Fig. 10 and Fig. 11 it is clear that for day 4 , day 5 and day 6 which were cloudy days with occasional rain in between, the indoor daylight falls well below recommended intensity. Daylight intensity at all the positions especially at the centre of the room was very poor. Again, lighting intensities varies all over the day causing uncomfortable indoor environment. The indoor daylight intensity on a rainy day is compared with the comfort light intensity in Fig. 12. 


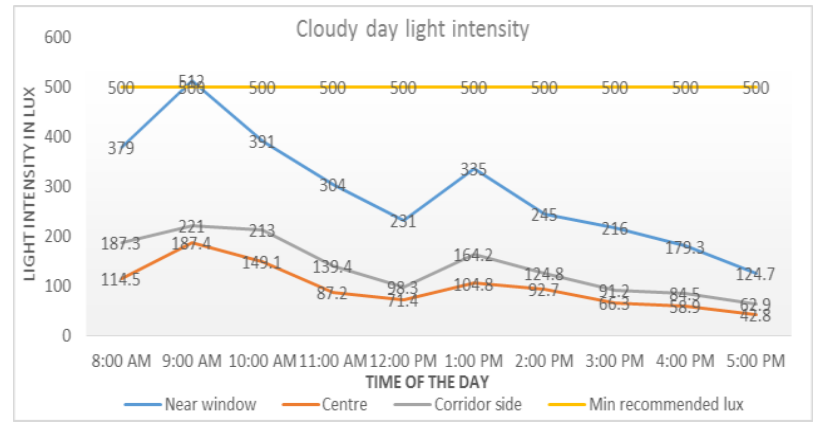

Fig. 12. Variation of daylight intensity on a rainy day

\subsection{Analysis of daylight intensity in the hostel rooms}

The intensity of indoor daylight of the hostel rooms varies over different factors like time of the day, position of the room, floor on which the room is located etc. A number of 24 hostel rooms are studied over a period of 1 month in the month of September located at different positions and floors all over the hostel. It was found that position of the room plays a significant role in the indoor lighting environment of the hostel rooms.

When graphs are plotted from the recorded data it was seen that rooms located in the "A" wing (eastern facing) gets a good amount of morning light but decreases rapidly after noon whereas "B" wing (western facing) rooms have darker morning indoor environment as compared to A side rooms but gets max daylight between 1PM to 3PM in the afternoon hours. Fig.13 shows the graphical representation of variation of average daylight intensity of rooms located at Wing A and Wing B.

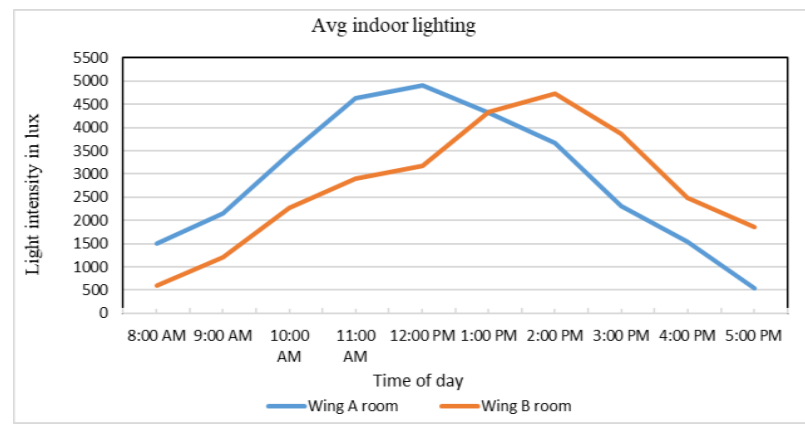

Fig. 13. Variation of avg. daylight intensity among the "A" and "B" wing.

Again, when the distribution of lighting intensity inside the room was analysed, it was found that lighting intensity at the farthest side from the window is lesser by a great margin from intensity near the windows. It means that despite a proper lighting near the windows, artificial lighting is still needed in the hostel rooms for a comfortable indoor environment. One of the reasons for this can be due the installation of windows, which are not directly on the wall but built outside the wall in a box like design. This design restricts daylight only to the areas near the window keeping the other parts comparatively darker. The variation of indoor light from window side to the farthest side over the time is shown in Fig. 14.

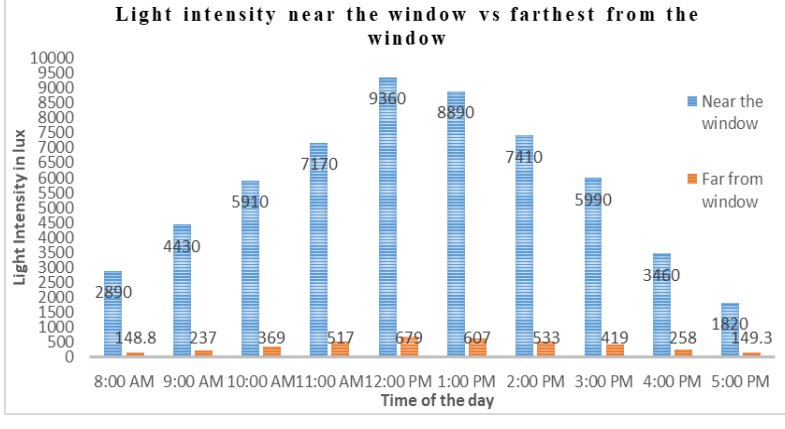

Fig. 14. Variation of daylight intensity at different position

\section{Analysis of the questionnaire survey}

To check the reliability of the responses to confirm whether those responses can be used in this study to analyse the results, $\mathrm{P}$ value was found out by using the software SPSS. For a set of three variables, correlation of variable 1 was found out to be significant at the 0.01 level and the correlations of variables 2 and 3 are found to be significant at the 0.05 level. From this data it can be assumed that the responses of the survey is reliable enough to use in the analysis of the result for this study. For the questionnaire survey, a nine point scale was used for recording the responses of the occupants regarding the indoor comfort. For this scale, 1 refers to extremely unfavourable and 9 being the extremely favourable conditions of indoor environment. By analysing the responses through graphs it was found that majority of the occupants found the indoor lighting environment comfortable as most of the response values are in between 5 and 8. Daylight distribution was felt to be unfavourable by a few students specially who were seating far from the window sides. A large number of students reported to face uncomfortable indoor environments like glare, thermal irritation etc. with majority of the response values lying between 5 and 7 depicting a noticeable presence of uncomfortable environment but not on the extreme levels. Again regarding the effect of lighting on mood of the students, responses suggested that almost every students find the indoor daylight to affect their mood on some level. With majority of the responses lying between the ranges of 4 to 7 , it can be analysed that indoor lighting environment plays a considerable role with the psychology of the occupants. Fig. 15 to Fig. 18 shows the graphical representation of the questionnaire survey data.

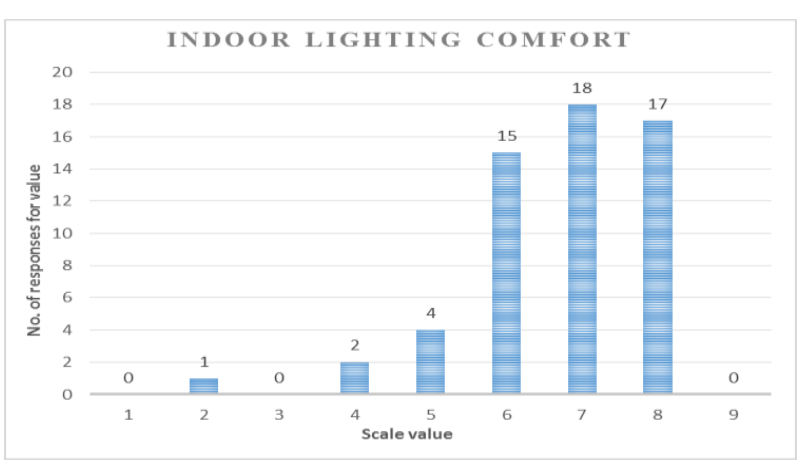

Fig. 15. Responses for indoor daylight comfort 


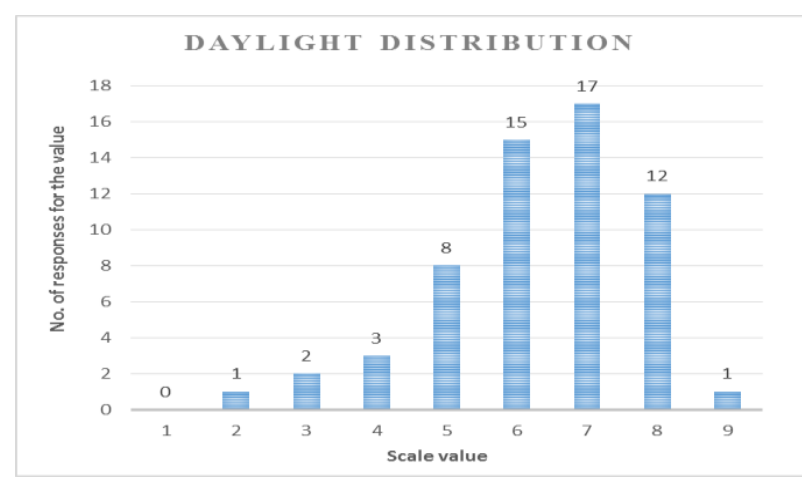

Fig. 16. Responses for indoor daylight distribution

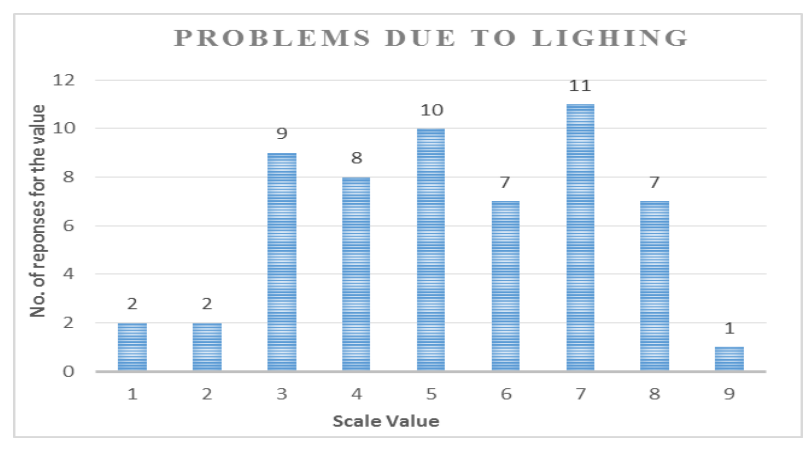

Fig. 17. Responses for problems caused by daylight

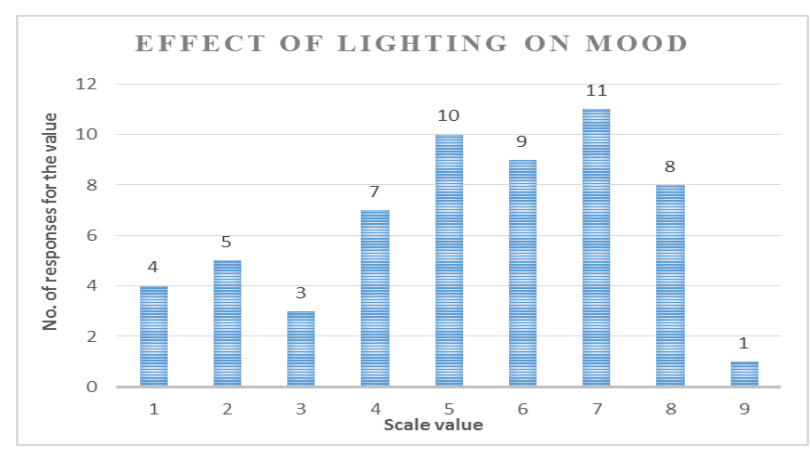

Fig. 18. Responses for effect of daylight on mood of the occupants

\section{Conclusion}

This study was done to analyse the adaptive lighting comfort in the classrooms of educational building and student hostel rooms. Daylight intensity was recorded in 3 classrooms for a week and also for 24 hostel rooms over a period of month. Also a questionnaire survey was distributed among students to collect their responses regarding the daylight sensation and indoor comfort environment. This responses were analysed with the help of graphs plotted from the recorded data. It was found that majority of the respondents found the daylight intensity between 250-400 lux comfortable which is below the recommended intensity of 500 lux for study purpose in classrooms. Need of artificial lighting was felt only below the intensity level of 200-250 lux. Students sitting at the window sides reported glare and thermal discomfort when the lighting intensity is recorded more than 800 lux. For the classrooms, the students sitting in the centre found the distribution of indoor lighting to be poor and felt the need of artificial lighting during early morning or late evening hours and also during the cloudy days. Majority of the students found the corridor side lighting environment to be more suitable. In the hostel rooms, students reported the distribution of daylight in the rooms to be unsatisfactory. Also some respondents reported thermal uncomforting at night due to high intensity of light in the room during the evening hour because of west facing orientation of the rooms. Students preferred daylight over artificial lighting as per their responses and also the moods of the students were reported to be dependent on indoor lighting environment. Students reported that dim indoor lighting than the comfortable intensity induces sleepiness during the study hours and uneven distribution of daylight, flickering of light causes lapse in concentration.

Indoor lighting is a major factor controlling the comfort level of occupants and plays even bigger role in educational buildings. Efforts should be made to make a room visually more comfortable to the occupants from the design phase itself. Curtains should be provided in all the classrooms to avoid undesirable bright light inside the room. Vegetation around the classrooms should not be allowed to grow too dense so that it may obstruct the natural daylight coming to the building. More efficient window designs should be applied to make the light distribution inside the room comfortable. Now a days with the help of BIM and Automation software, occupant friendly indoor lighting environment in classrooms and hostel room are easier to designs and implement. The scope for future research is high in this field as more and more people are giving emphasis on indoor comforting with each passing day.

\section{References}

1.J. Hummelgaard, P. Juhl, K. O. Sæbjörnsson, G. Clausen, J. Toftum, and G. Langkilde, Build. Environ. 42, 4051 (2007).

2.A. Wagner, E. Gossauer, C. Moosmann, T. Gropp, and R. Leonhart, Energy Build. 39, 758 (2007).

3.D. M. Franco-Duran and G. Mejia A, Proc. Constr. Res. Congr. 20162039 (2016).

4.J. A. Jakubiec and C. F. Reinhart, LEUKOS - J. Illum. Eng. Soc. North Am. 12, 185 (2016).

5.T. M. Chung and J. Burnett, Indoor Built Environ. 9, 335 (2000).

6.CIBSE: Code for Interior Lighting. London, Chartered Institution of Building Services Engineers, 1994 (1994).

7.IESNA: Lighting Handbook, Ed 8. New York, Illuminating Engineering Society of North America, 1993 (1993).

8.A. T. P. So and L. M. Leung, Archit. Sci. Rev. 41, 113 (1998).

9.P. Ricciardi and C. Buratti, Build. Environ. 127, 23 (2018).

10.N. Gentile, T. Goven, T. Laike, and K. Sjoberg, Light. Res. Technol. 50, 631 (2018). 